\title{
Reversal of type 2 diabetes: normalisation of beta cell function in association with decreased pancreas and liver triacylglycerol
}

\author{
E. L. Lim • K. G. Hollingsworth • B. S. Aribisala • \\ M. J. Chen - J. C. Mathers • R. Taylor
}

Received: 22 March 2011 / Accepted: 5 May 2011 /Published online: 9 June 2011

(C) The Author(s) 2011. This article is published with open access at Springerlink.com

\begin{abstract}
Aims/hypothesis Type 2 diabetes is regarded as inevitably progressive, with irreversible beta cell failure. The hypothesis was tested that both beta cell failure and insulin resistance can be reversed by dietary restriction of energy intake.

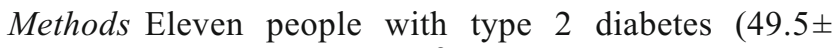
2.5 years, BMI $33.6 \pm 1.2 \mathrm{~kg} / \mathrm{m}^{2}$, nine male and two female) were studied before and after 1, 4 and 8 weeks of a $2.5 \mathrm{MJ}$ (600 kcal)/day diet. Basal hepatic glucose output, hepatic and peripheral insulin sensitivity and beta cell function were measured. Pancreas and liver triacylglycerol content was measured using three-point Dixon magnetic resonance imaging. An age-, sex- and weight-matched group of eight non-diabetic participants was studied.

Results After 1 week of restricted energy intake, fasting plasma glucose normalised in the diabetic group (from $9.2 \pm$ 0.4 to $5.9 \pm 0.4 \mathrm{mmol} / 1 ; p=0.003$ ). Insulin suppression of hepatic glucose output improved from $43 \pm 4 \%$ to $74 \pm 5 \%$ ( $p=$ 0.003 vs baseline; controls $68 \pm 5 \%$ ). Hepatic triacylglycerol content fell from $12.8 \pm 2.4 \%$ in the diabetic group to $2.9 \pm$ $0.2 \%$ by week $8(p=0.003)$. The first-phase insulin response increased during the study period $(0.19 \pm 0.02$ to $0.46 \pm$

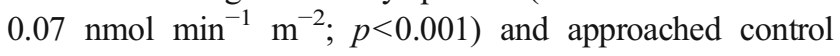

E. L. Lim • K. G. Hollingsworth • B. S. Aribisala • M. J. Chen • R. Taylor $(\bowtie)$

Magnetic Resonance Centre, Institute of Cellular Medicine, Campus for Ageing and Vitality, Newcastle University,

Newcastle upon Tyne NE4 5PL, UK

e-mail: roy.taylor@ncl.ac.uk

J. C. Mathers

Human Nutrition Research Centre,

Institute for Ageing and Health, Newcastle University,

Newcastle upon Tyne, UK values $\left(0.62 \pm 0.15 \mathrm{nmol} \mathrm{m^{-1 }} \mathrm{m}^{-2} ; p=0.42\right)$. Maximal insulin response became supranormal at 8 weeks $(1.37 \pm$

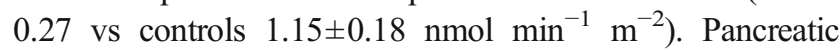
triacylglycerol decreased from $8.0 \pm 1.6 \%$ to $6.2 \pm 1.1 \%$ $(p=0.03)$.

Conclusions/interpretation Normalisation of both beta cell function and hepatic insulin sensitivity in type 2 diabetes was achieved by dietary energy restriction alone. This was associated with decreased pancreatic and liver triacylglycerol stores. The abnormalities underlying type 2 diabetes are reversible by reducing dietary energy intake.

Keywords Insulin secretion - Liver fat - Low energy diet . Pancreatic fat · Type 2 diabetes

\section{Abbreviation \\ ffm Fat-free mass}

\section{Introduction}

Type 2 diabetes has long been regarded as a chronic progressive condition, capable of amelioration but not cure. A steady rise in plasma glucose occurs irrespective of the degree of control or type of treatment [1]. Beta cell function declines linearly with time, and after 10 years more than $50 \%$ of individuals require insulin therapy [2]. The underlying changes in beta cell function have been well described [3, 4], and beta-cell mass decreases steadily during the course of type 2 diabetes [5,6]. Overall, there is strong evidence that type 2 diabetes is inexorably progressive, with a high likelihood of insulin therapy being eventually required to maintain good glycaemic control.

However, type 2 diabetes is clearly reversible following bariatric surgery [7]. The normalisation of plasma glucose 
concentration follows within days of surgery, long before major weight loss has occurred, and it has become widely assumed that the protective effects of gastrointestinal surgery are mediated by altered secretion of incretin hormones $[8,9]$. Improved control of blood glucose in type 2 diabetes by moderate energy restriction has been demonstrated by others [10]. We have hypothesised that the profound effect of a sudden negative energy balance on the metabolism could explain the post-bariatric surgery effect [11] and, specifically, that the decrease in the intracellular fatty acid concentrations in the liver would lead to a lower export of lipoprotein triacylglycerol to the pancreas, with the release of beta cells from the chronic inhibitory effects of excess fatty acid exposure.

This study was designed to test the hypothesis that acute negative energy balance alone reverses type 2 diabetes by normalising both beta cell function and insulin sensitivity. We examined the restoration of first-phase and total insulin response as well as hepatic and peripheral insulin sensitivity. Additionally, to examine the mechanistic basis of observed outcomes, we quantified the change in fat content of the pancreas and liver.

\section{Methods}

Participants Individuals with type 2 diabetes (age 3565 years, $\mathrm{HbA}_{1 \mathrm{c}} 6.5-9.0 \%$ [ $48-75 \mathrm{mmol} / \mathrm{mol}$ ], diabetes duration $<4$ years, stable BMI $25-45 \mathrm{~kg} / \mathrm{m}^{2}$ ) were recruited. Participants were excluded if being treated with thiazolidinediones, insulin, steroids or beta-blockers, with a serum creatinine $>150 \mathrm{mmol} / \mathrm{l}$, with a serum alanine transaminase level $>2.5$-fold above the upper limit of the reference range, or if there were contraindications for MRI. Statin therapy was continued. The study protocol was approved by the Newcastle upon Tyne Ethics Committee No. 2, and all participants gave their informed consent. Sulfonylurea (two individuals) was discontinued 2 months, and metformin (seven individuals) 1 week, before the baseline study. Dietary adherence was assessed using capillary ketone levels (Xceed Optium; Abbott Diabetes Care, Maidenhead, UK). Three individuals failed to comply with the diet (two during the first week and one during weeks 4-8), and one left the study for an unrelated medical reason. Hence 11 individuals (nine male and two female, age $49.5 \pm 2.5$ years) completed the study.

Nine control participants matched for weight, age and sex were also studied (seven male, two female, age $49.7 \pm 2.5$ years; Table 1). These participants had no family history of diabetes, were taking no medication and had normal glucose metabolism as confirmed by a standard $75 \mathrm{~g}$ OGTT.

Experimental protocol Participants were asked to continue their habitual pattern of eating until the start of the study. Assessments of beta cell function, insulin sensitivity, liver and pancreatic fat content and total body fat were carried out at baseline immediately prior to dietary intervention (day -1 ), and after 1, 4 and 8 weeks of the very-low-energy diet. A group of matched non-diabetic controls were studied on one occasion only, without dietary intervention.

After the baseline measurements, individuals with type 2 diabetes started the diet, which consisted of a liquid diet formula $(46.4 \%$ carbohydrate, $32.5 \%$ protein and $20.1 \%$ fat; vitamins, minerals and trace elements; $2.1 \mathrm{MJ} /$ day [510 kcal/day]; Optifast; Nestlé Nutrition, Croydon, UK). This was supplemented with three portions of non-starchy vegetables such that total energy intake was about $2.5 \mathrm{MJ}$ $(600 \mathrm{kcal}) /$ day. Participants were provided with suggestions of vegetable recipes to enhance compliance by varying daily eating. They were also encouraged to drink at least 21 of water or other energy-free beverages each day, and asked to maintain their habitual level of physical activity. Ongoing support and encouragement was provided by means of regular telephone contact. At the end of the 8 week intervention participants returned to normal eating but were provided with information about portion size and healthy eating.

The striking results seen at 8 weeks demanded experimental follow-up, and additional ethics permission was obtained to repeat the MRI studies and carry out OGTTs 12 weeks after completing the dietary intervention.

Hepatic glucose production and insulin sensitivity After an overnight fast, cannulae were inserted into an antecubital vein for infusion and the contralateral wrist vein for arterialised
Table 1 Anthropometric data before and during the 8 weeks of dietary intervention in comparison with control individuals

Data are mean $\pm \mathrm{SE}$

${ }^{\dagger} p<0.05$ individuals with type 2 diabetes vs controls; $* p<0.05$ type 2 diabetes baseline vs later

\begin{tabular}{lccccc}
\hline Variable & \multicolumn{1}{c}{ Controls } & \multicolumn{1}{c}{ Baseline } & \multicolumn{1}{l}{ Week 1 } & Week 4 & Week 8 \\
\hline Weight $(\mathrm{kg})$ & $101.5 \pm 3.4$ & $103.7 \pm 4.5$ & $99.7 \pm 4.5^{*}$ & $94.1 \pm 4.3^{*}$ & $88.4 \pm 4.3^{* \dagger}$ \\
BMI $\left(\mathrm{kg} / \mathrm{m}^{2}\right)$ & $33.4 \pm 0.9$ & $33.6 \pm 1.2$ & $32.3 \pm 1.2^{*}$ & $30.5 \pm 1.2^{*}$ & $28.7 \pm 1.3^{* \dagger}$ \\
Fat mass $(\mathrm{kg})$ & $36.2 \pm 2.7$ & $39.0 \pm 3.5$ & $36.6 \pm 3.6^{*}$ & $31.7 \pm 3.7^{*}$ & $26.3 \pm 4.0^{*}$ \\
ffm $(\mathrm{kg})$ & $64.7 \pm 3.8$ & $64.7 \pm 3.0$ & $63.2 \pm 3.1$ & $62.4 \pm 3.0^{*}$ & $62.1 \pm 3.0^{*}$ \\
Waist circumference $(\mathrm{cm})$ & $105.0 \pm 1.5$ & $107.4 \pm 2.2$ & $104.4 \pm 2.2^{*}$ & $99.7 \pm 2.4^{*}$ & $94.2 \pm 2.5^{* \dagger}$ \\
Hip circumference $(\mathrm{cm})$ & $109.8 \pm 2.4$ & $109.5 \pm 2.9$ & $108.3 \pm 2.7^{*}$ & $105.0 \pm 2.6^{*}$ & $99.5 \pm 2.6^{* \dagger}$ \\
WHR & $0.96 \pm 0.02$ & $0.98 \pm 0.02$ & $0.97 \pm 0.02$ & $0.95 \pm 0.01$ & $0.95 \pm 0.01$ \\
\hline
\end{tabular}


blood sampling. $\left[6^{\prime} 6^{\prime}-{ }^{2} \mathrm{H}\right]$ glucose $(98 \%$ enriched; Cambridge Isotope Laboratories, Andover, MA, USA) was used to determine hepatic glucose production [12, 13], and basal rates were calculated during the last $30 \mathrm{~min}$ of the $150 \mathrm{~min}$ basal period. Preinfusion enrichment of isotope was insignificant throughout. An isoglycaemic-hyperinsulinaemic clamp (insulin infusion rate $40 \mathrm{mU} \mathrm{m}^{-2} \mathrm{~min}^{-1}$ ) was initiated at 0 min [14]. Isoglycaemia was used to ensure that the true fasting condition of each participant could be observed at each study time point. Each participant was clamped at the glucose level observed at the end of the basal period. Whole-body insulin sensitivity was determined during the last $30 \mathrm{~min}$ of the hyperinsulinaemic glucose clamp as whole-body glucose disposal corrected for glucose space and urinary loss [14, 15]. Glucose metabolic clearance rates during steady-state conditions were calculated by dividing whole-body insulin sensitivity by steady-state plasma glucose.

Assessment of beta cell function Sixty minutes after the clamp test, two consecutive $30 \mathrm{~min}$ square-wave steps of hyperglycaemia ( 2.8 and $5.6 \mathrm{mmol} / \mathrm{l}$ above baseline) were achieved by a priming glucose dose followed by variable $20 \%$ glucose infusion [16]. Blood samples for determination of plasma glucose, insulin and C-peptide concentrations were obtained every $2 \mathrm{~min}$ for the first $10 \mathrm{~min}$ and every $5 \mathrm{~min}$ for the other $20 \mathrm{~min}$ of each step. An arginine bolus was administered during the second step of hyperglycaemia, followed by sampling every $2 \mathrm{~min}$ for $10 \mathrm{~min}$. Insulin secretion rate was calculated using a computerised program implementing a regularisation method of deconvolution [17] and using a population model of C-peptide kinetics [18].

Magnetic resonance measurements A Philips $3.0 \mathrm{~T}$ Achieva scanner and six-channel cardiac coil (Philips Healthcare, Best, the Netherlands) were used to acquire three gradient-echo scans with adjacent out-of-phase and in-phase echoes (time to repetition/time to echo/averages/ flip angle $=50 \mathrm{~ms} / 3.45,4.60,5.75 \mathrm{~ms} / 1 / 30^{\circ}$, matrix $160 \times$ 109 , field of view $400-480 \mathrm{~mm}$ to suit participant size with $70 \%$ phase field of view). Six slices were acquired within a $17 \mathrm{~s}$ breath-hold to cover the liver with slice thickness $10 \mathrm{~mm}$ and the pancreas with slice thickness $5 \mathrm{~mm}$. The data were analysed in MATLAB (MathWorks, Cambridge, UK) to produce separate fat and water images [19]. The fat content of the image was expressed as a percentage of the total signal per voxel. The intraorgan fat percentage was evaluated from five liver regions of interest and two pancreatic regions of interest, defined and averaged in a blinded fashion by one observer (K. G. Hollingsworth). The pancreatic fat data represent solely intrapancreatic fat, and the liver data avoid contamination from blood vessels and gallbladder. This was achievable because of the data processing after image acquisition, allowing manual selection of wholly intraorgan volume from the anatomical slice. The interscan Bland-Altman repeatability coefficients were $0.5 \%$ for the liver and $0.9 \%$ for the pancreas.

Body composition and anthropometry Percentage body fat was measured following an overnight fast using airdisplacement plethysmography (BOD POD Express; Life Measurement, Concord, CA, USA). Waist and hip circumferences were measured with the participants in a relaxed standing posture. Waist circumference was taken at the mid-point between the anterior superior iliac spine and the lower edge of the rib cage, and hip circumference at the level of the greater trochanter. All measurements were made throughout the study period by a single observer (E. L. Lim).

Analytical procedures Plasma glucose concentration was measured by the glucose oxidase method (YSI glucose analyser; Yellow Springs, OH, USA), plasma insulin and Cpeptide concentrations by ELISA (Dako, Ely, UK), plasma triacylglycerol by lipase with released glycerol measured by a Roche Cobas centrifugal analyser using a colorimetric assay (ABX Diagnostics, Montpellier, France) and $\mathrm{HbA}_{1 \mathrm{c}}$ by a Biorad HPLC (TOSOH Corporation, Tokyo, Japan). ${ }^{2} \mathrm{H}$ atom percent excess in plasma glucose was determined using a Thermo 'Voyager' single quadrupole mass spectrometer with Thermo 'Trace' gas chromatograph (Thermo Scientific, Waltham, MA, USA).

Statistical methods Statistical analyses were performed using SPSS 17.0 software (SPSS Inc., Chicago, IL, USA). Data are presented as mean \pm SE. Statistical comparisons between diabetes and control groups were performed using the Student's $t$ test, while within-group differences were determined using a paired $t$ test. Changes of sequential data within experiments were evaluated by repeated measures one-way ANOVA with post hoc Bonferroni testing where appropriate. Correlations were examined using the Spearman rank test. Statistical significance was accepted at $p<0.05$.

\section{Results}

Plasma glucose and insulin After 1 week of dietary intervention, fasting plasma glucose decreased from 9.2 \pm 0.4 to $5.9 \pm 0.4 \mathrm{mmol} / 1$ ( $p=0.003$; Fig. 1$)$ and was not significantly different from that of the non-diabetic control group $(5.3 \pm 0.1 \mathrm{mmol} / \mathrm{l} ; p=0.18)$. It remained stable for the rest of the 8 week study $(5.7 \pm 0.5 \mathrm{mmol} / 1$ at weeks 4 and 8 ; $p=0.52$ compared with control). $\mathrm{HbA}_{1 \mathrm{c}}$ decreased from 


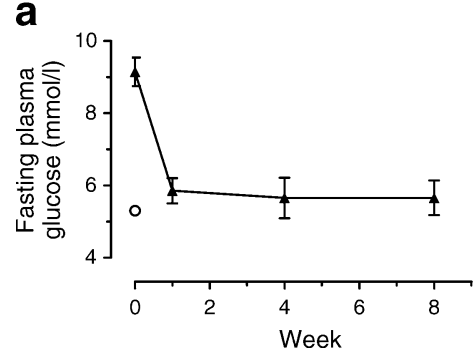

Fig. 1 Effect of 8 weeks of dietary intervention on (a) plasma glucose, (b) hepatic glucose production (HGP) and (c) hepatic triacylglycerol content (TG) for diabetic participants (black triangles). b

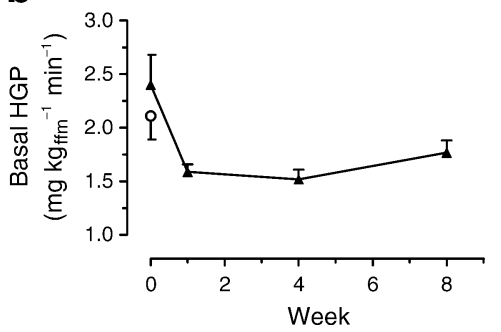

C

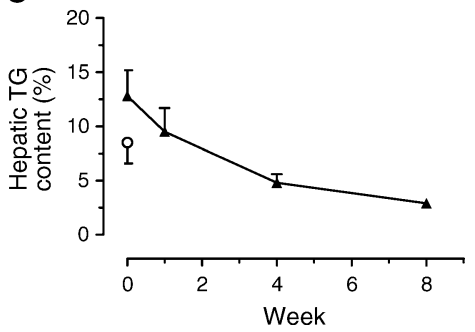

White circles indicate the mean for the weight-matched non-diabetic control group. Data are shown as mean $\pm \mathrm{SE}$

$7.4 \pm 0.3 \%(57 \pm 3 \mathrm{mmol} / \mathrm{mol})$ and at 8 weeks was not significantly different from non-diabetic control values $(6.0 \pm 0.2$ vs $5.7 \pm 0.1 \%[42 \pm 2$ vs $39 \pm 1 \mathrm{mmol} / \mathrm{mol}], p=$ $0.27)$ Fasting plasma insulin fell from $151 \pm 31$ to $73 \pm 10$ $\mathrm{pmol} / \mathrm{l}$ after 1 week $(p=0.03)$ and to $65 \pm 15 \mathrm{pmol} / \mathrm{l}$ by 8 weeks ( $p=0.03$ vs baseline; $p=0.04$ vs control). Fasting plasma C-peptide decreased similarly (Table 2 ).

During the isoglycaemic clamp, plasma glucose was clamped at $4.6 \pm 0.1 \mathrm{mmol} / 1$ in the control group compared with $7.0 \pm 0.3 \mathrm{mmol} / \mathrm{l}$ in the diabetes group at baseline $(p<0.001)$. At week 1 , the achieved clamped plasma glucose level was $4.8 \pm 0.2 \mathrm{mmol} / 1$ ( $p<0.001$ vs baseline) in the diabetes individuals and this was similar at weeks 4 and $8(4.8 \pm 0.3$ and $4.8 \pm 0.4$, respectively, $p<$ 0.001 vs baseline).

Hepatic insulin sensitivity and hepatic triacylglycerol content Basal hepatic glucose production decreased significantly during the first week of energy restriction $(2.40 \pm 0.28$ to $1.59 \pm 0.07 \mathrm{mg} \mathrm{kg}_{\mathrm{ffm}}{ }^{-1} \mathrm{~min}^{-1} ; p=0.05$ ), remained decreased compared with baseline for the rest of the study, and at 8 weeks was not significantly different from that of the control group $\left(1.71 \pm 0.11\right.$ vs $2.11 \pm 0.22 \mathrm{mg} \mathrm{kg}_{\mathrm{ffm}}{ }^{-1} \mathrm{~min}^{-1}$ respectively; $p=0.60$; Fig. 1). At baseline, hepatic insulin sensitivity, assessed by the suppression of hepatic glucose production by insulin infusion, was $43 \pm 4 \%$ in the diabetic group compared with $68 \pm 5 \%$ in the control group $(p=0.001)$. During the first week of energy restriction, there was a marked improvement in hepatic insulin responsiveness, with insulin suppression of hepatic glucose production increasing to $74 \pm 5 \%$ ( $p=0.003$ vs baseline).

Hepatic triacylglycerol content decreased by $30 \pm 5 \%$ during week 1 of intervention ( $p<0.001)$, becoming similar to control values $(p=0.75)$. It continued to decline throughout the intervention period to reach the normal range for non-obese individuals [20] $(2.9 \pm 0.2 \% ; p=0.003$; Fig. 1), i.e. a total reduction of $70 \pm 5 \%$. At baseline, hepatic triacylglycerol content was $8.5 \pm 1.9 \%$ in the control group compared with $12.8 \pm 2.4 \%$ in the diabetic group ( $p=0.14$ ). Hepatic triacylglycerol at baseline correlated with BMI in

Table 2 Metabolic response to 8 weeks of dietary intervention in participants with type 2 diabetes in comparison with controls

\begin{tabular}{|c|c|c|c|c|c|}
\hline Fasting concentration & Controls & Baseline & Week 1 & Week 4 & Week 8 \\
\hline $\mathrm{HbA}_{1 \mathrm{c}}(\%)$ & $5.7 \pm 0.1$ & $7.4 \pm 0.3^{\dagger \dagger}$ & $7.1 \pm 0.3^{* \dagger \dagger}$ & $6.5 \pm 0.2^{* * \dagger}$ & $6.0 \pm 0.2^{* *}$ \\
\hline $\mathrm{HbA}_{1 \mathrm{c}}(\mathrm{mmol} / \mathrm{mol})$ & $39 \pm 1$ & $57 \pm 3^{\dagger \dagger}$ & $55 \pm 3^{* \dagger}$ & $47 \pm 3^{* * \dagger}$ & $42 \pm 2^{* *}$ \\
\hline Plasma glucose $(\mathrm{mmol} / \mathrm{l})$ & $5.3 \pm 0.1$ & $9.2 \pm 0.4^{\dagger \dagger}$ & $5.9 \pm 0.4^{* *}$ & $5.7 \pm 0.6^{* *}$ & $5.7 \pm 0.5^{* *}$ \\
\hline Plasma insulin (pmol/1) & $115 \pm 27$ & $151 \pm 31$ & $73 \pm 10^{*}$ & $57 \pm 11^{*}$ & $65 \pm 15^{* \dagger}$ \\
\hline Plasma C-peptide (nmol/l) & $1.06 \pm 0.12$ & $1.21 \pm 0.20$ & $1.14 \pm 0.16$ & $1.19 \pm 0.19$ & $0.86 \pm 0.11$ \\
\hline Triacylglycerol (mmol/l) & $1.8 \pm 0.1$ & $2.4 \pm 0.5$ & $1.2 \pm 0.1^{* \dagger}$ & $1.0 \pm 0.1^{* \dagger \dagger}$ & $1.3 \pm 0.3^{* \dagger}$ \\
\hline NEFA (mmol/l) & $0.57 \pm 0.07$ & $0.69 \pm 0.06$ & $0.93 \pm 0.05^{* \dagger \dagger}$ & $0.81 \pm 0.08^{\dagger}$ & $0.72 \pm 0.06$ \\
\hline Cholesterol (mmol/l) & $5.1 \pm 0.3$ & $4.0 \pm 0.3^{\dagger}$ & $3.3 \pm 0.3^{*+\dagger}$ & $2.8 \pm 0.2^{* \dagger \dagger}$ & $3.2 \pm 0.3^{\dagger \dagger}$ \\
\hline LDL-cholesterol $(\mathrm{mmol} / \mathrm{l})$ & $3.2 \pm 0.3$ & $1.7 \pm 0.2^{\dagger \dagger}$ & $1.8 \pm 0.4^{\dagger \dagger}$ & $1.0 \pm 0.2^{* \dagger \dagger}$ & $1.3 \pm 0.2^{\dagger \dagger}$ \\
\hline HDL-cholesterol (mmol/l) & $1.1 \pm 0.1$ & $1.1 \pm 0.1$ & $1.0 \pm 0.1$ & $1.1 \pm 0.1$ & $1.1 \pm 0.1$ \\
\hline ALT (U/l) & $33 \pm 3$ & $46 \pm 7$ & $61 \pm 10^{* \dagger}$ & $44 \pm 3^{\dagger}$ & $33 \pm 3$ \\
\hline Gamma GT (U/l) & $39 \pm 5$ & $62 \pm 12$ & $49 \pm 8$ & $25 \pm 4^{\dagger}$ & $26 \pm 5^{* *}$ \\
\hline
\end{tabular}

Data are mean $\pm \mathrm{SE}$

${ }^{\dagger} p<0.05$ vs controls; ${ }^{\dagger \dagger} p<0.005$ vs controls; ${ }^{*} p<0.05$ vs type 2 diabetes baseline; ${ }^{* *} p<0.005$ vs type 2 diabetes baseline

ALT, alanine transaminase; gamma GT, $\gamma$-glutamyltransferase 
the controls $(R \mathrm{~s}=0.71 ; p<0.05)$ but not in the diabetic group $(R \mathrm{~s}=-0.50 ; p=0.12)$.

Beta cell sensitivity to glucose and pancreas triacylglycerol content Fasting insulin secretion rate decreased from $0.10 \pm$ 0.01 to $0.06 \pm 0.01 \mathrm{nmol} \mathrm{min}{ }^{-1} \mathrm{~m}^{-2}$ during the first week $(p<0.05)$ and remained constant thereafter. During the insulin secretion test, the planned step increases in plasma glucose concentration of +2.8 and $+5.6 \mathrm{mmol} / 1$ were achieved (Fig. 2). In the diabetes individuals, peak insulin secretion rate at 6 min was minimal at baseline $(0.19 \pm 0.02$

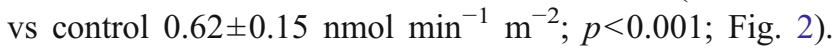
The first-phase insulin response steadily increased and was significantly different from baseline by 8 weeks $(0.29 \pm$ $0.05,0.34 \pm 0.06$ and $0.46 \pm 0.07 \mathrm{nmol} \mathrm{min}{ }^{-1} \mathrm{~m}^{-2}$ at 1,4 and 8 weeks; $p=0.20, p=0.09, p=0.006$, respectively). At 8 weeks in the individuals with type 2 diabetes, the insulin secretion rate was not significantly different from control

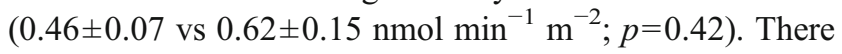

was an increase in arginine-induced insulin response after 1 week (from $0.72 \pm 0.11$ to $0.95 \pm 0.19 \mathrm{nmol} \mathrm{min}{ }^{-1} \mathrm{~m}^{-2}$; $p<0.006$ ), and by 8 weeks it was completely normalised $\left(1.37 \pm 0.27\right.$ vs $1.15 \pm 0.18 \mathrm{nmol} \mathrm{m^{-1 }} \mathrm{m}^{-2} ; p=0.77$ vs control; $p<0.03$ vs baseline; Fig. 2). It was $38 \%$ lower in the participants with type 2 diabetes at baseline compared with the controls $(0.72 \pm 0.11$ vs $1.15 \pm$ $\left.0.18 \mathrm{nmol} \mathrm{min}^{-1} \mathrm{~m}^{-2} ; p=0.04\right)$.

Pancreatic triacylglycerol content in the diabetic group was $8.0 \pm 1.6 \%$ and fell steadily to $6.2 \pm 1.1 \%$ after 8 weeks ( $p=0.03$; Fig. 3). In control individuals, pancreatic triacylglycerol content was $6.0 \pm 1.3 \%$ ( $p=0.17$ compared with participants with type 2 diabetes at baseline). There was no correlation with BMI in either the control or the diabetic group $(R \mathrm{~s}=0.31$, $p=0.36 ; R \mathrm{~s}=0.01, p=0.98$, respectively).

Peripheral insulin sensitivity There was no significant change in peripheral insulin sensitivity expressed as glucose disposal rates during the entire study. Insulin-stimulated glucose
Fig. 2 Insulin secretion test data in controls and in diabetic participants at each time point. a Plasma glucose levels achieved in each group. Insulin section rate (ISR) obtained in (b) the non-diabetic control group, (c) the diabetic group at baseline, (d) the diabetic group at 1 week of the diet, (e) the diabetic group at 4 weeks and (f) the diabetic group at 8 weeks. Data are shown as mean $\pm \mathrm{SE}$

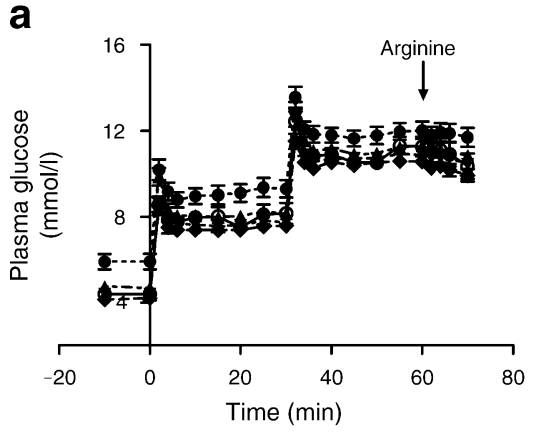

b
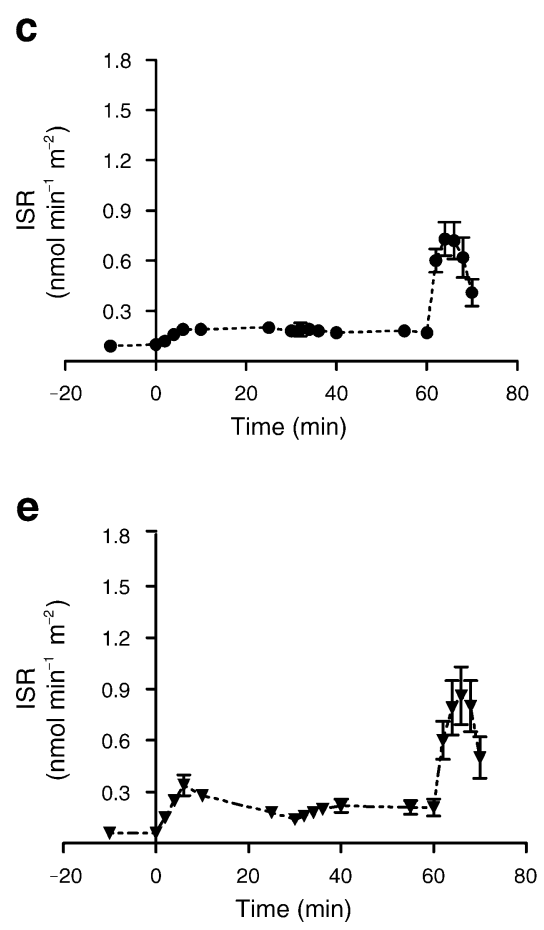

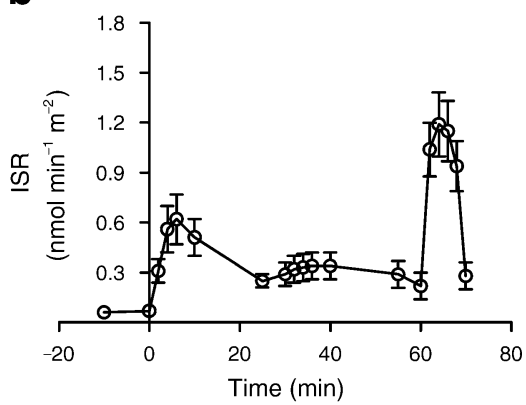

d

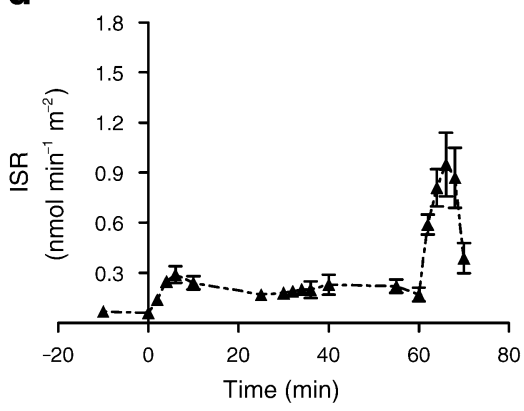

f

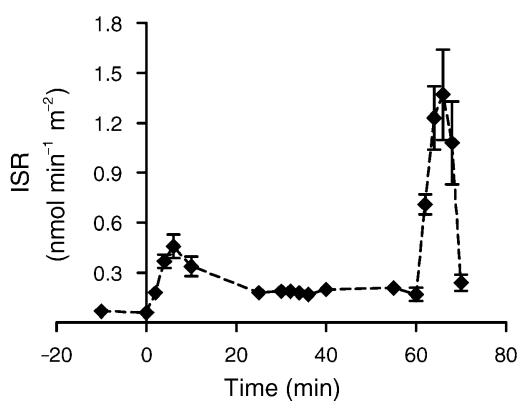



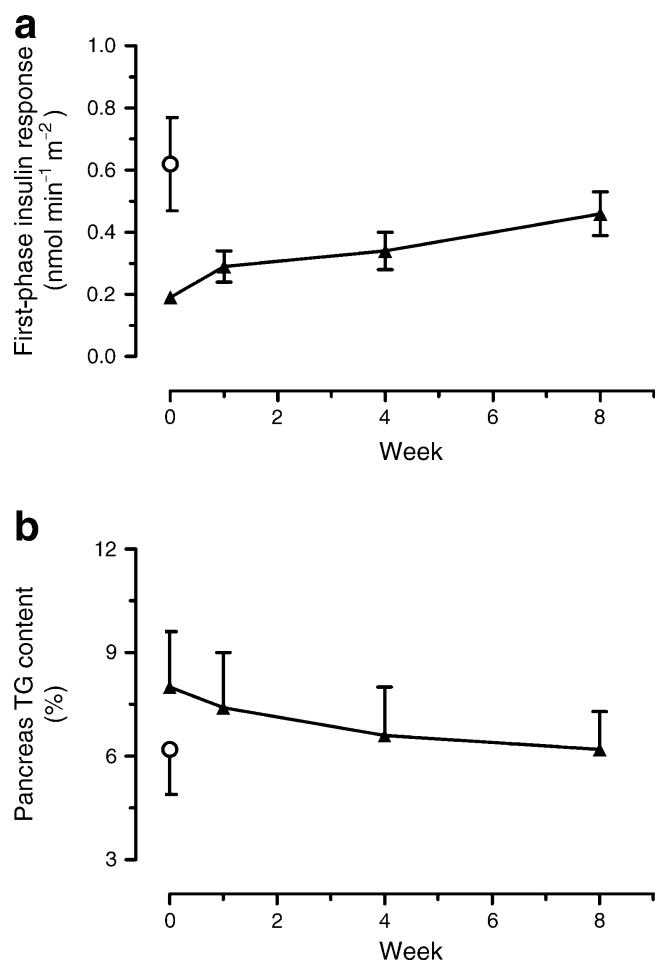

Fig. 3 a Change in first-phase insulin response, and (b) change in pancreas triacylglycerol (TG) content during the 8 week dietary intervention in diabetic individuals (black triangles). White circles indicate the mean for the weight-matched non-diabetic control group. Data are shown as mean $\pm \mathrm{SE}$

disposal was $3.83 \pm 0.23$ and $4.36 \pm 0.36 \mathrm{mg} \mathrm{kg}_{\mathrm{ffm}}{ }^{-1} \mathrm{~min}^{-1}$ (where $\mathrm{ffm}$ is fat-free mass) at baseline and 8 weeks, respectively $(p=0.21)$. Change in glucose metabolic clearance rate was examined to correct for the difference in clamp glucose levels between study days. Fasting plasma glucose decreased between baseline and week 1. There was no significant effect of the dietary intervention on glucose metabolic clearance rate at either 1 or 4 weeks $(3.1 \pm 0.3$ vs $4.23 \pm 0.34$ and $4.21 \pm 0.36 \mathrm{ml} \mathrm{kg}_{\text {ffm }}{ }^{-1} \min ^{-1}$, respectively), but improvement was demonstrable by week 8 (5.2 \pm $0.5 \mathrm{ml} \mathrm{kg}{ }_{\mathrm{ffm}}^{-1} \mathrm{~min}^{-1} ; p=0.003$ for baseline vs 8 weeks; control group $5.2 \pm 0.4 \mathrm{ml} \mathrm{kg}_{\mathrm{ffm}}{ }^{-1} \mathrm{~min}^{-1} ; p=0.98$ ).

Weight and body composition Average weight loss during the 8 weeks of dietary intervention was $15.3 \pm 1.2 \mathrm{~kg}$, equivalent to $15 \pm 1 \%$ of initial body weight (Table 1 ). Weight loss was $3.9 \pm 0.2 \mathrm{~kg}$ during the first week $(61 \%$ of which was fat loss), $5.7 \pm 0.6 \mathrm{~kg}$ ( $86 \%$ as fat) between weeks 1 and 4, and $5.7 \pm 0.7 \mathrm{~kg}$ (94\% as fat) during the final 4 weeks. Both waist and hip circumference decreased to the same extent and WHR remained unchanged during the 8 weeks (Table 1 ).

Plasma lipids Plasma triacylglycerol levels halved during the first week of dietary energy restriction $(2.4 \pm 0.5$ to $1.2 \pm$
$0.1 \mathrm{mmol} / \mathrm{l} ; p<0.02$ ) and remained constant thereafter (Table 2). Total cholesterol also decreased, and HDLcholesterol remained unchanged during the study period (Table 2). Fasting plasma NEFA levels were modestly but not significantly higher in the diabetic participants compared with the matched controls at baseline $(0.69 \pm$ 0.06 vs $0.57 \pm 0.07 \mathrm{mmol} / 1 ; p=0.24)$. During the study period, fasting NEFA in the participants with diabetes increased significantly at week $1(0.93 \pm 0.05 \mathrm{mmol} / \mathrm{l}$; $p=0.03$ vs baseline). With continued hypoenergetic intake, plasma NEFA declined steadily towards baseline values $(0.81 \pm 0.08$ and $0.72 \pm 0.06 \mathrm{mmol} / \mathrm{l}$ at weeks 4 and 8 , respectively).

Post-intervention observation At follow-up 12 weeks after completion of the dietary intervention, mean weight gain was $3.1 \pm 1.0 \mathrm{~kg}$. Hepatic triacylglycerol remained low and unchanged $(2.9 \pm 0.2$ vs $3.0 \pm 0.3 \% ; p=0.80)$, and pancreatic triacylglycerol decreased further to a small extent $(6.2 \pm 1.1 \mathrm{vs}$ $5.7 \pm 1.1 \% ; p=0.005)$. $\mathrm{HbA}_{1 \mathrm{c}}$ was unchanged $(6.0 \pm 0.2$ vs $6.2 \pm 0.1 \%[42 \pm 2$ vs $44 \pm 1 \mathrm{mmol} / \mathrm{mol}] ; p=0.10)$ and fasting plasma glucose increased modestly $(5.7 \pm 0.5$ vs $6.1 \pm$ $0.2 \mathrm{mmol} / \mathrm{l} ; p<0.01)$, with a $2 \mathrm{~h}$ OGTT plasma glucose of $10.3 \pm 1.0 \mathrm{mmol} / \mathrm{l}$. Three participants had recurrence of diabetes as judged by a $2 \mathrm{~h}$ post-load plasma glucose $>11.1 \mathrm{mmol} / \mathrm{l}$. Fasting plasma insulin concentrations were unchanged ( $57 \pm 11$ vs $65 \pm 15 \mathrm{pmol} / \mathrm{l})$ and fasting plasma NEFA decreased further $(0.72 \pm 0.06$ vs $0.54 \pm 0.05 \mathrm{mmol} / \mathrm{l}$; $p<0.02$ ). One individual was unavailable for retesting, having had surgery for an ovarian cyst (non-malignant).

\section{Discussion}

This study demonstrates that the twin defects of beta cell failure and insulin resistance that underlie type 2 diabetes can be reversed by acute negative energy balance alone. A hierarchy of response was observed, with a very early change in hepatic insulin sensitivity and a slower change in beta cell function. In the first 7 days of the reduced energy intake, fasting blood glucose and hepatic insulin sensitivity fell to normal, and intrahepatic lipid decreased by $30 \%$. Over the 8 weeks of dietary energy restriction, beta cell function increased towards normal and pancreatic fat decreased. Following the intervention, participants gained $3.1 \pm 1.0 \mathrm{~kg}$ body weight over 12 weeks, but their $\mathrm{HbA}_{1 \mathrm{c}}$ remained steady while the fat content of both pancreas and liver did not increase. The data are consistent with the hypothesis that the abnormalities of insulin secretion and insulin resistance that underlie type 2 diabetes have a single, common aetiology, i.e. excess lipid accumulation in the liver and pancreas [11]. This provides a unified hypothesis to explain a common disease that previously 
appeared to require separate disease processes affecting the pancreas and insulin-sensitive tissues.

Absence of rapid insulin secretion in response to a rise in plasma glucose is the hallmark of type 2 diabetes $[3,21]$, and the decline in beta cell function determines the progression towards a need for insulin therapy [2]. However, conventional therapy, even with sulfonylurea, fails to produce more than a small increase in the first-phase insulin response. As a consequence, the rapidity and extent of return of beta cell function in response to dietary energy restriction in the present study is striking. It supports the accumulating information on the inhibitory effect of fatty acids on insulin secretion in vitro and in vivo [22-24] and is the first direct evidence in humans that the beta cell defect of type 2 diabetes is reversible by sustained negative energy balance. Prolonged elevation of plasma fatty acids in humans decreases insulin secretion [25, 26], and it has previously been shown that there is an association between pancreatic fat content and type 2 diabetes [27-29]. Prior to the onset of spontaneous diabetes in rodents, both total pancreatic fat and islet triacylglycerol content increase sharply [30, 31]. In vitro, chronic saturated fatty acid exposure of beta cells inhibits the acute insulin response to glucose, and removal of fatty acids allows recovery of this response [32].

The present data provide clear evidence that decreasing total pancreatic fat is associated with a return of beta cell function. However, it is probable that the negative effect on beta cell function is exerted by toxic intermediaries such as diacylglycerol and ceramides, which change rapidly in response to acute metabolic changes [33], rather than by stored triacylglycerol per se, which acts as an index of fatty acid intermediary concentration. There was no correlation between indices of insulin secretion and pancreatic fat, which suggests that there are individual thresholds of tolerance for such toxic intermediaries rather than a simple dose-response relationship within the pancreas.

Fasting plasma glucose concentration is determined by the rate of hepatic glucose production, and hepatic insulin sensitivity is inversely proportional to intrahepatic lipid content [13, 34-36]. Moderate weight loss has previously been shown to be associated with a fall in intrahepatic fat content $[10,37]$. Petersen et al. have previously reported improved liver and no significant change in muscle insulin sensitivity measured by euglycaemic hyperinsulinaemic clamps after 8 weeks of moderate energy restriction in type 2 diabetes [10]. A very low energy intake has been observed to lower liver fat content in healthy obese individuals within days [38]. The present study demonstrates for the first time the early time course with which both hepatic fat stores and hepatic glucose production fall in response to dietary restriction in type 2 diabetes. Change in peripheral insulin sensitivity played no part in the early return of normoglycaemia. It is possible that the sharp rise in plasma NEFA observed after 1 week of the hypocaloric diet could have prevented a change in peripheral insulin sensitivity even though this did not prevent the rapid improvement of hepatic insulin sensitivity.

We have previously hypothesised that establishing the pathophysiological changes that accompany the reversal of type 2 diabetes will illuminate the sequence of changes determining the onset of the disease [11]. This twin-cycle hypothesis was informed by observations following bariatric surgery, especially the demonstration that fasting blood glucose concentrations fell within days after biliopancreatic diversion [39]. As these changes occur before substantial weight loss, it has become widely accepted that bariatric surgery exerts such rapid effects by changes in incretin hormones. However, the extent of change in incretins is modest, not always present in type 2 diabetes, and absent after gastric banding [40-43]. Little attention has been paid to the potential role of a sudden negative energy balance on glucose metabolism after bariatric surgery, although a recent small study suggested that the improvement in insulin resistance in the first week after surgery can be attributed to negative energy balance alone [44]. Increased glucagon-like peptide-1 secretion following bariatric surgery compared with a hypocaloric diet has been reported, but the oral glucose load used in the presence of a gastroenterostomy is likely to explain the early rapid rise in both plasma glucose and the incretin, occasionally with the symptoms of early dumping [45].

The limitations of this study must be considered. First, the sample size was necessarily small to allow the application of gold standard methods for metabolic investigation and examination by magnetic resonance techniques. However, the participants were drawn from the population with type 2 diabetes, and their clinical and anthropometric characteristics were typical for the condition.

Second, pancreatic fat measurements included intraorgan adipocyte fat content because current methodology precludes the assessment of the more mechanistically important islet intracellular fatty acid content. Animal data suggest that the two variables are linked [31]. Although pancreatic fat content was $30 \%$ higher in the diabetic group, the study was powered to demonstrate responses to the dietary intervention rather than to test differences from weight-matched non-diabetic individuals. No correlation was observed between pancreatic fat and BMI within the restricted range of BMI examined in this study.

Third, the participants were selected to have had a relatively short duration of type 2 diabetes (up to 4 years), and further studies must establish the extent of reversibility with longer duration type 2 diabetes. In addition, further studies are required to determine the long-term outcome in respect of glucose regulation as the observations made after 12 weeks of return to a normal diet were necessarily limited. 
Finally, the raised liver fat levels despite metabolic normality in some controls can be considered in the light of the recent description of the PNPLA3 gene [46]. The $G$ allele of this gene determines high liver fat levels, but in a form that is not associated with metabolic abnormality. This provides a clear genetic basis for the observed individual variation in susceptibility to insulin resistance despite raised liver fat content, and offers a partial explanation of the overlapping hepatic fat levels in type 2 diabetic and control groups. It is likely that other genetic factors yet to be defined underlie the differing individual levels of susceptibility to pancreatic fat accumulation in terms of inhibition of glucose-dependent insulin secretion.

This study demonstrates for the first time the time course of a return of normal beta cell function and hepatic glucose output by acute restriction of dietary energy intake in individuals with type 2 diabetes. The changes occurred in association with decreases in pancreatic and liver triacylglycerol concentrations. This new insight allows an understanding of the causality of type 2 diabetes in individuals as well as in populations. It carries major implications for information to be given to newly diagnosed patients, who should know that they have a potentially reversible condition and not one that is inevitably progressive.

Acknowledgements We thank L. Morris, C. Smith and T. Hodgson for magnetic resonance radiography, A. Lane for GC-MS analyses, J. Gerrard for research nurse support and K. Heron for dietary advice. We are most grateful to the volunteers for their enthusiastic participation. This study was funded wholly by project grant RD08/ 0003713 from Diabetes UK. Nestlé UK provided the Optifast on request but had no other input into the research.

E.L.L performed research, analysed data and wrote the manuscript. K.H. designed the research, analysed the data and edited the manuscript. B.A. analysed the data and edited the manuscript. M.J.C. performed research and contributed to the manuscript. J.M. designed the research and edited the manuscript. R.T. designed the research, analysed the data and reviewed/edited the manuscript. All authors approved the final version to be published.

Duality of interest The authors declare that there is no duality of interest associated with this manuscript.

Open Access This article is distributed under the terms of the Creative Commons Attribution Noncommercial License which permits any noncommercial use, distribution, and reproduction in any medium, provided the original author(s) and source are credited.

\section{References}

1. UK Prospective Diabetes Study Group (1999) Intensive blood glucose control with sulphonylureas or insulin compared with conventional treatment and risk of complications in patients with type 2 diabetes (UKPDS 33). Lancet 352:837-853
2. Prospective Diabetes Study Group UK (1995) Overview of 6 years' therapy of type II diabetes: a progressive disease. UK Prospective Diabetes Study 16. Diabetes 44:1249-1258

3. Weyer C, Bogardus C, Mott DM, Pratley RE (1999) The natural history of insulin secretory dysfunction and insulin resistance in the pathogenesis of type 2 diabetes mellitus. J Clin Invest 104:787-794

4. Kahn SE (2003) The relative contributions of insulin resistance and beta-cell dysfunction to the pathophysiology of type 2 diabetes. Diabetologia 46:3-19

5. Butler AE, Janson J, Bonner-Weir S, Ritzel R, Rizza RA, Butler PC (2003) Beta-cell deficit and increased beta-cell apoptosis in humans with type 2 diabetes. Diabetes 52:102-110

6. Hanley SC, Austin E, Assouline-Thomas B et al (2010) \{beta $\}-$ Cell mass dynamics and islet cell plasticity in human type 2 diabetes. Endocrinology 151:1462-1472

7. Pories WJ, Caro JF, Flickinger EG, Meelheim HD, Swanson MS (1987) The control of diabetes mellitus (NIDDM) in the morbidly obese with the Greenville Gastric Bypass. Ann Surg 206:316323

8. Rubino F, Forgione A, Cummings DE et al (2006) The mechanism of diabetes control after gastrointestinal bypass surgery reveals a role of the proximal small intestine in the pathophysiology of type 2 diabetes. Ann Surg 244:741-749

9. Kashyap SR, Daud S, Kelly KR et al (2010) Acute effects of gastric bypass vs gastric restrictive surgery on beta-cell function and insulinotropic hormones in severely obese patients with type 2 diabetes. Int J Obes (Lond) 34:462-471

10. Petersen KF, Dufour S, Befroy D, Lehrke M, Hendler RE, Shulman GI (2005) Reversal of nonalcoholic hepatic steatosis, hepatic insulin resistance, and hyperglycemia by moderate weight reduction in patients with type 2 diabetes. Diabetes 54:603-608

11. Taylor R (2008) Pathogenesis of type 2 diabetes: tracing the reverse route from cure to cause. Diabetologia 51:1781-1789

12. Hother-Nielsen O, Henriksen JE, Holst JJ, Beck-Nielsen H (1996) Effects of insulin on glucose turnover rates in vivo: isotope dilution vs constant specific activity technique. Metabolism 45:82-91

13. Ravikumar B, Gerrard J, Dalla Man C et al (2008) Pioglitazone decreases fasting and postprandial endogenous glucose production in proportion to decrease in hepatic triglyceride content. Diabetes 57:2288-2295

14. DeFronzo RA, Tobin JD, Andres R (1979) Glucose clamp technique: a method for quantifying insulin secretion and resistance. Am J Physiol 237:E214-E223

15. Rizza RA, Mandarino LJ, Gerich JE (1981) Dose-response characteristics for effects of insulin on production and utilization of glucose in man. Am J Physiol 240:E630-E639

16. Toschi E, Camastra S, Sironi AM et al (2002) Effect of acute hyperglycemia on insulin secretion in humans. Diabetes 51 (Suppl 1):S130-S133

17. Hovorka R, Soons PA, Young MA (1996) ISEC: a program to calculate insulin secretion. Comput Meth Programs Biomed 50:253-264

18. Van Cauter E, Mestrez F, Sturis J, Polonsky KS (1992) Estimation of insulin secretion rates from C-peptide levels. Comparison of individual and standard kinetic parameters for C-peptide clearance. Diabetes 41:368-377

19. Glover GH, Schneider E (1991) Three-point Dixon technique for true water/fat decomposition with B0 inhomogeneity correction. Magn Reson Med 18:371-383

20. Szczepaniak LS, Nurenberg P, Leonard D et al (2005) Magnetic resonance spectroscopy to measure hepatic triglyceride content: prevalence of hepatic steatosis in the general population. Am J Physiol Endocrinol Metab 288:E462-E468 
21. Pfeifer MA, Halter JB, Porte D (1981) Insulin secretion in diabetes mellitus. Am J Med 70:579-588

22. Igoillo-Esteve M, Marselli L, Cunha DA et al (2010) Palmitate induces a pro-inflammatory response in human pancreatic islets that mimics CCL2 expression by beta cells in type 2 diabetes. Diabetologia 53:1395-1405

23. Cnop M (2008) Fatty acids and glucolipotoxicity in the pathogenesis of type 2 diabetes. Biochem Soc Trans 36:348-352

24. Noushmehr H, D'Amico E, Farilla L et al (2005) Fatty acid translocase (FAT/CD36) is localized on insulin-containing granules in human pancreatic beta-cells and mediates fatty acid effects on insulin secretion. Diabetes 54:472-481

25. Carpentier A, Zinman B, Leung N et al (2003) Free fatty acidmediated impairment of glucose-stimulated insulin secretion in nondiabetic Oji-Cree individuals from the Sandy Lake community of Ontario, Canada: a population at very high risk for developing type 2 diabetes. Diabetes 52:1485-1495

26. Kashyap S, Belfort R, Gastaldelli A et al (2003) A sustained increase in plasma free fatty acids impairs insulin secretion in nondiabetic subjects genetically predisposed to develop type 2 diabetes. Diabetes 52:2461-2474

27. Tushuizen ME, Bunck MC, Pouwels PJ et al (2007) Pancreatic fat content and beta-cell function in men with and without type 2 diabetes. Diabetes Care 30:2916-2921

28. Saisho Y, Butler AE, Butler PC (2008) Pancreatic fat content and beta-cell function in men with and without type 2 diabetes: response to Tushuizen et al. Diabetes Care 31:e38, author reply e39

29. Saisho Y, Butler AE, Meier JJ et al (2007) Pancreas volumes in humans from birth to age one hundred taking into account sex, obesity, and presence of type-2 diabetes. Clin Anat 20:933-942

30. Lee Y, Hirose H, Ohneda M, Johnson JH, McGarry JD, Unger RH (1994) Beta-cell lipotoxicity in the pathogenesis of non-insulindependent diabetes mellitus of obese rats: impairment in adipocyte-beta-cell relationships. Proc Natl Acad Sci USA 91:1087810882

31. Lee Y, Lingvay I, Szczepaniak LS, Ravazzola M, Orci L, Unger RH (2010) Pancreatic steatosis: harbinger of type 2 diabetes in obese rodents. Int J Obes (Lond) 34:396-400

32. Morgan NG, Dhayal S, Diakogiannaki E, Welters HJ (2008) The cytoprotective actions of long-chain mono-unsaturated fatty acids in pancreatic beta-cells. Biochem Soc Trans 36:905-908

33. Erion DM, Shulman GI (2010) Diacylglycerol-mediated insulin resistance. Nat Med 16:400-402

34. Perseghin G, Bonfanti R, Magni S et al (2006) Insulin resistance and whole body energy homeostasis in obese adolescents with fatty liver disease. Am J Physiol Endocrinol Metab 291:E697E703

35. Gastaldelli A, Cusi K, Pettiti M et al (2007) Relationship between hepatic/visceral fat and hepatic insulin resistance in nondiabetic and type 2 diabetic subjects. Gastroenterology 133:496-506

36. D'Adamo E, Cali AM, Weiss R et al (2010) Central role of fatty liver in the pathogenesis of insulin resistance in obese adolescents. Diabetes Care 33:1817-1822

37. Tiikkainen M, Bergholm R, Vehkavaara S et al (2003) Effects of identical weight loss on body composition and features of insulin resistance in obese women with high and low liver fat content. Diabetes 52:701-707

38. Kirk E, Reeds DN, Finck BN, Mayurranjan SM, Patterson BW, Klein S (2009) Dietary fat and carbohydrates differentially alter insulin sensitivity during caloric restriction. Gastroenterology 136:1552-1560

39. Guidone C, Manco M, Valera-Mora E et al (2006) Mechanisms of recovery from type 2 diabetes after malabsorptive bariatric surgery. Diabetes 55:2025-2031

40. Morinigo R, Lacy AM, Casamitjana R, Delgado S, Gomis R, Vidal J (2006) GLP-1 and changes in glucose tolerance following gastric bypass surgery in morbidly obese subjects. Obes Surg 16:1594-1601

41. Rodieux F, Giusti V, D’Alessio DA, Suter M, Tappy L (2008) Effects of gastric bypass and gastric banding on glucose kinetics and gut hormone release. Obesity (Silver Spring) 16:298-305

42. Knop FK (2009) Resolution of type 2 diabetes following gastric bypass surgery: involvement of gut-derived glucagon and glucagonotropic signalling? Diabetologia 52:2270-2276

43. Rubino F, Gagner M, Gentileschi P et al (2004) The early effect of the Roux-en-Y gastric bypass on hormones involved in body weight regulation and glucose metabolism. Ann Surg 240:236242

44. Isbell JM, Tamboli RA, Hansen EN et al (2010) The importance of caloric restriction in the early improvements in insulin sensitivity after Roux-en-Y gastric bypass surgery. Diabetes Care 33:1438-1442

45. Laferrere B, Teixeira J, McGinty J et al (2008) Effect of weight loss by gastric bypass surgery vs hypocaloric diet on glucose and incretin levels in patients with type 2 diabetes. J Clin Endocrinol Metab 93:2479-2485

46. He S, McPhaul C, Li JZ et al (2010) A sequence variation (I148M) in PNPLA3 associated with nonalcoholic fatty liver disease disrupts triglyceride hydrolysis. J Biol Chem 285:67066715 